CORRESPONDENCE

\section{Resolving the Azorean knot: a response to Carine \& Schaefer (2010)}

\section{ABSTRACT}

Carine \& Schaefer (Journal of Biogeography, 2010, 37, 77-89) suggest that the lack of past climate oscillations in the Azores may have contributed to the low plant endemism in this archipelago compared to that of the Canary Islands, a pattern they term the Azorean diversity enigma. Here we challenge their hypothesis, and discuss how the particular characteristics of the Azores may have driven current diversification patterns in this archipelago. We argue that the restricted number of Azorean endemic species and their wide distribution is explicable by the geological, geographical and ecological attributes of the archipelago. That is, the Azores are too young, too small, and too environmentally homogeneous to have hosted many in situ diversification events, so they do not host as many endemic species as other Macaronesian archipelagos, such as Madeira and especially the Canary Islands.

Keywords Azores, Canary Islands, climate oscillations, diversification, endemism, isolation, Macaronesia, sea-level oscillations, seamounts, stepping stones.

Island diversity results from the interplay of three fundamental processes: immigration, extinction and speciation (MacArthur \& Wilson, 1967; Rosenzweig, 1995; Whittaker \& Fernández-Palacios, 2007). The patterns of diversification on the Macaronesian archipelagos, particularly on the Canary Islands and the Azores, have been extensively discussed over the past few years (see Serrano et al., 2010, and references therein). In spite of their isolation, the Azores are characterized by the widespread distribution of most archipelago endemic species, which results in comparatively few single-island endemics (hereafter SIEs) (Borges et al., 2010). Three hypotheses have been put forward to explain the 'enigma' of low Azorean diversification: (1) the islands are too young to have hosted extensive in situ diversification events; (2) the constituent lineages are too young to have diversified very far; and (3) the low habitat diversity of the Azorean islands provides few opportunities for adaptive radiation (see Carine \& Schaefer, 2010, for a fuller treatment of the papers originally introducing these hypotheses).

Carine \& Schaefer (2010; hereafter C\&S) challenged these three hypotheses using published phylogenetic data of Macaronesian endemic flowering plants. Additionally, C\&S used distributional and ecological data from nine angiosperm genera with endemic congeners in the Azores to infer speciation modes, i.e. inter-island allopatric speciation or adaptive radiation. They also used the available molecular phylogeny for a single genus, Pericallis, present across Macaronesia, to estimate divergence times for the lineages present in both the Azores and the Canary Islands, showing that the Canarian clades diversified in a shorter time period than the Azorean clade. Based on these data, C\&S concluded that none of above mentioned hypotheses can satisfactorily explain the limited diversification in Azorean plants, especially in comparison with the Canary Islands. Instead, C\&S proposed that past climate oscillations may have contributed to the anomalously low Azorean endemism. Briefly, they argued that climate has been more unstable in the Canaries than in the Azores during the late Pleistocene and Holocene. Such higher variability would have driven the recent diversification of the Canarian flora by fostering repeated episodes of inter-island allopatry in contrast to the Azores, where the more stable climate resulted in lower diversification rates.

Here we challenge the C\&S hypothesis, and in particular their assumption of higher dynamism of the Canarian climate. We do this keeping in mind that in a subsequent paper (Schaefer et al., 2011) the same authors presented the opposite pattern for part of the Azorean angiosperm flora. Based on molecular data from 69 populations of eight endemic Azorean taxa, Schaefer et al. (2011) found evidence for higher incidence of single island endemism and a lower proportion of widespread taxa in the endemic Azorean flora compared to the figures presented in C\&S, due to overlooked genetic diversity (i.e. cryptic speciation). Similarly, although the distributional and ecological data used by C\&S implied that ecological speciation processes may be more common than allopatric ones, the molecular data of Schaefer et al. (2011) imply the opposite. In consequence, they recast C\&S's interpretation. For example, Schaefer et al. (2011) argue that C\&S introduced two possible explanations for the Azorean enigma, namely an imbalance in the past climatic oscillations across Macaronesia and the incompleteness - and thus inadequacy - of the knowledge on the Azorean flora. However, a close reading of C\&S reveals that only the former hypothesis was suggested as a possible explanation of the observed patterns, the latter being just a cautionary note. Furthermore, while C\&S stated: 'We demonstrate that none of them [i.e. the three hypotheses proposed to explain Azorean floristic diversity; our addition] satisfactorily explains the limited incidence of inter-island vicariance', according to Schaefer et al. (2011): 'Carine \& Schaefer (2010) concluded that neither island age ... nor age of endemic lineages ... nor ecological diversity ... at least considered individually [our emphasis], could explain the patterns observed in the Azores flora'. Later, Schaefer et al. (2011, p. 1352) revive the three hypotheses rejected by $C \& S$ as potential explanations for the Azorean enigma. They further introduce the 'Linnean shortfall', i.e. inadequacies in taxonomic data for Azorean plants, as a possible explanation.

It is indisputable that phylogeographical data based on molecular evidence can aid in understanding the processes building up biodiversity in space and time (see Avise, 
2009). However, when such evidence is only available for a limited number of lineages, extrapolating the patterns observed to the level of the whole biota may be misleading. The best way to build on current work may be to adopt a rigorous hypothesis-testing framework such as statistical phylogeography (Knowles, 2009), and to combine the fragmentary phylogeographical information with the more comprehensive data on species' distributions that are available for the Azores.

\section{IS CLIMATIC STABILITY A PLAU- SIBLE HYPOTHESIS FOR THE LOW DIVERSIFICATION OF THE AZOREAN BIOTA?}

Contrary to C\&S'S conclusions, it is unlikely that climatic fluctuations were greater in the Canary Islands than in the Azores during the late Pleistocene and Holocene. The palaeoclimatic studies collated by C\&S (Rogerson et al., 2004; Björck et al., 2006; Ortiz et al., 2006) describe different parts of the climate system that are not directly comparable, each referring to a single archipelago or just a few islands. Thus, they provide partial views of past climatic changes in the North Atlantic archipelagos. In contrast, studies using a single source of evidence on a broader geographical extent show higher fluctuations in temperature, salinity and sea circulation in the Azorean than in the Canarian regions (e.g. planktonic foraminiferal assemblages; Crowley, 1981; Morey et al., 2005). The climatic projections of recent atmospheric circulation models calibrated with palaeoclimatic evidence (Overpeck et al., 1989; Braconnot et al., 2007) also indicate that changes in climate have been more pronounced in the Azores than in the Canaries during the glacial cycles, especially in terms of the precipitation regime (Table 1 ).

We also find it unlikely that the rapid and abrupt transitions from humid to arid conditions on the easternmost islands and islets of the Canaries (Ortiz et al., 2006) could have caused the high diversification observed in this archipelago as invoked by C\&S. On the one hand, their limited temporal extent (about $50 \mathrm{kyr}$ ) is not enough to explain the high numbers of endemics in the Canary Islands (e.g. the dated Pericallis phylogenetic tree provided by $\mathrm{C} \& \mathrm{~S}$, their fig. 4 ); on the other hand, the rapid pace of these fluctuations (often 1-3 kyr between transitions; Ortiz et al., 2006; see also Kim et al., 2007) could have caused repeated episodes of extinction rather than adaptive radiations as postulated by C\&S. Note that in the absence of additional information, both processes would lead to similar phylogenetic patterns. Importantly, the palaeoclimatic evidence provided by Ortiz et al. (2006) refers only to Lanzarote and Fuerteventura, which host comparatively fewer SIE vascular plants, land snails and arthropods than the rest of the Canary Islands (Arechavaleta et al., 2010); the pattern remains similar even if Mahan, the single late Pleistocene palaeoisland consisting of Lanzarote and Fuerteventura, is considered. The oldest and easternmost islands of the Canaries are already in their phase of erosion, host comparatively lower numbers of SIEs and exhibit higher extinction rates (Whittaker et al., 2008). The Azorean islands, on the contrary, are mainly at an immature stage of their ontogenetic cycle (sensu Whittaker et al., 2008), and hence most ongoing diversification processes are still too recent to have resulted in many new taxa.

\section{RESOLVING THE AZOREAN DIVERSITY ENIGMA}

The rejection of the climate stability hypothesis leaves the 'Azorean diversity enigma' unresolved. Here, we suggest that the restricted number of Azorean endemic species and their wide distribution is explicable by the geological, geographical and ecological attributes of the archipelago, i.e. the Azores are too young, too small and too environmentally homogeneous in comparison to other archipelagos of Macaronesia and especially the Canary Islands. We use existing knowledge and the available checklists for plants, arthropods and land snails to address why there are so few Azorean endemic species and why they are so widespread. Single-island endemic (SIE) species can provide potentially valuable insights into evolutionary dynamics. However, certain restrictions have to be kept in mind, since the number of SIEs is based on currently known extant distributions, and thus can be the result of extinction (on the island in question or elsewhere) and migration, rather than only of speciation (cf. Emerson \& Kolm, 2005; Whittaker et al., 2008). Available phylogeographical information is used to cross-check the patterns detected.

\section{Environmental heterogeneity}

In contrast to the high habitat diversity, elevation range and topographic complexity of Madeira and the Canary Islands, the Azorean islands are generally of low elevation (Table 2), relatively homogeneous in climate and show little elevational vegetation zonation (e.g. Sjögren, 1973; Borges et al., 2010).

Habitat diversity has a significant effect on the capacity of islands to host species (e.g. Hortal et al., 2009), and can foster diversification through cladogenesis. According to Stuessy et al. (2006), lowelevation islands with low habitat heterogeneity show high levels of anagenetic evolution, i.e. the formation of an endemic species from a colonist via any combination of adaptive process, population bottleneck, andor drift that does not lead to an increased number of species on an island, as in cladogenesis. It follows that the comparatively lower climatic and habitat diversity of the Azorean islands has resulted in less opportunity for ecological radiation, limiting the net diversification of the Azorean taxa when compared to other Macaronesian archipelagos. This seems to be confirmed by the limited phylogeographical data available, which indicate a preponderance of allopatric differentiation, without a major role for ecological speciation (e.g. Van Riel et al., 2005; Schaefer et al., 2011).

\section{Geological age}

Although a small part of Santa Maria's subaerial area is dated from $8.12 \mathrm{Ma}$ (Table 2), four of the nine Azorean islands are $<1$ Myr old, and the older ones also show high proportions of land of relatively recent origin. In fact, São Miguel (the largest island, and the closest to Santa Maria) first emerged as a small island (Nordeste Volcano, $4 \mathrm{Ma}$ ), and has evolved by both the gradual addition of land westwards (volcanic complex of Povoação and Água de $\mathrm{Pau} ;<1 \mathrm{Ma}$ ) and the later development of a large new island further west (Sete Cidades Volcano, 0.55 Ma), which connected to the older eastern part very recently (volcanic complex of Picos, $0.05 \mathrm{Ma}$ ). Thus, in total, $62 \%$ of the current Azorean land is younger than $1 \mathrm{Myr}$ old (see discussion in Triantis et al., 2010). By contrast, the volcanic provinces that the Canaries and Madeiran archipelagos belong to are older than $60 \mathrm{Myr}$ (Table 2; see also Triantis et al., 2010 and Fernández-Palacios et al., 2011). This increases dramatically the likelihood that many lineages have persisted for long periods in these palaeoarchipelagos. Thus, the effective amount of 
Table 1 Changes in annual precipitation $(\mathrm{mm})$ and mean annual temperature $\left({ }^{\circ} \mathrm{C}\right)$ since the mid Holocene $(6 \mathrm{ka})$ and Last Glacial Maximum (21 ka) for the Azores and Canary Islands. Data on past climate were extracted from the ECHAM3 palaeoclimatic model (Braconnot et al., 2007; see also http://pmip.lsce.ipsl.fr), and correspond to conditions at sea level (note that actual climate would have varied according to the interaction with the topography of each island). Changes in temperature and precipitation were calculated as the difference between current and past values (i.e. temperature and precipitation anomalies from the present; see Araújo et al., 2008), e.g. negative values indicate more precipitation at $6 \mathrm{ka}$ than today.

\begin{tabular}{|c|c|c|c|c|}
\hline \multirow[b]{2}{*}{ Island(s) } & \multicolumn{2}{|c|}{$\begin{array}{l}\text { Change in precipitation } \\
(\mathrm{mm}) \text { since }\end{array}$} & \multicolumn{2}{|c|}{$\begin{array}{l}\text { Change in temperature } \\
\left({ }^{\circ} \mathrm{C}\right) \text { since }\end{array}$} \\
\hline & $6 \mathrm{ka}$ & $21 \mathrm{ka}$ & $6 \mathrm{ka}$ & $21 \mathrm{ka}$ \\
\hline \multicolumn{5}{|l|}{ Azores } \\
\hline Flores \& Corvo & -41 & 247 & 0.1 & 5.7 \\
\hline Faial, Pico \& São Jorge & -9 & 258 & 0 & 4.4 \\
\hline Terceira \& Graciosa & -1 & 247 & 0 & 4.3 \\
\hline São Miguel & 30 & 268 & 0 & 3.7 \\
\hline Santa Maria & 37 & 250 & 0.3 & 3.6 \\
\hline \multicolumn{5}{|l|}{ Canary Islands } \\
\hline El Hierro & 0 & 9 & 0 & 4.3 \\
\hline La Palma \& La Gomera & 0 & 35 & 0.1 & 4 \\
\hline Tenerife & 2 & 26 & 0 & 4 \\
\hline Gran Canaria & 5 & 6 & 0.1 & 4.8 \\
\hline Fuerteventura & -4 & 28 & 0 & 4 \\
\hline Lanzarote & 4 & 46 & 0.2 & 4.1 \\
\hline
\end{tabular}

Table 2 Properties of the island systems, diversity and endemism of land snails, vascular plants (spermatophytes and pteridophytes) and arthropods in the Azores, Madeira and Canary Islands. For the geological age of the archipelagos the age of the oldest existing island is reported (the maximum age of the island chain the archipelago belongs to is given in parentheses). For elevation we also give the mean value and the respective standard deviation for all the islands of the archipelago in parentheses. Data correspond to the numbers of native species $\left(S_{\mathrm{Nat}}\right)$, archipelago endemics (ArE) and single-island endemics (SIE), as well as the percentage of native species that are single-island endemics (\% SIE) on each island. Data are derived from Borges et al. (2008) (Madeira), Borges et al. (2010) (Azores) and Arechavaleta et al. (2010) (Canary Islands). The data for the Azorean land snails were provided by Antonio Frias Martins (University of Azores, Ponta Delgada, unpublished data).

\begin{tabular}{|c|c|c|c|c|c|c|c|c|c|c|c|c|c|c|c|c|}
\hline \multirow[b]{2}{*}{ Archipelago } & \multirow{2}{*}{$\begin{array}{l}\text { Area } \\
\left(\mathrm{km}^{2}\right)\end{array}$} & \multirow{2}{*}{$\begin{array}{l}\text { Isolation } \\
(\mathrm{km})\end{array}$} & \multirow[b]{2}{*}{ Elevation (m) } & \multirow[b]{2}{*}{ Age (Myr) } & \multicolumn{4}{|c|}{ Land snails } & \multicolumn{4}{|c|}{ Vascular plants } & \multicolumn{4}{|c|}{ Arthropods } \\
\hline & & & & & $S_{\mathrm{Nat}}$ & ArE & SIE & $\%$ SIE & $S_{\mathrm{Nat}}$ & ArE & SIE & $\%$ SIE & $S_{\mathrm{Nat}}$ & $\mathrm{ArE}$ & SIE & $\%$ SIE \\
\hline Azores & 2328 & 1376 & $2351(1022 \pm 554)$ & $8.1(8.1)$ & 104 & 74 & 44 & 42.3 & 205 & 69 & 3 & 1.4 & 1077 & 252 & 101 & 9.3 \\
\hline Canary & 7496 & 115 & $3711(1924 \pm 1057)$ & $20(68)$ & 231 & 220 & 210 & 90.9 & 1389 & 539 & 310 & 22.3 & 6923 & 3079 & 1757 & 25.4 \\
\hline Madeira & 795 & 630 & $1850(1183 \pm 943)$ & $14(67)$ & 188 & 168 & 137 & 73.4 & 725 & 133 & 93 & 12.8 & 2029 & 889 & 772 & 38.0 \\
\hline
\end{tabular}

time available for diversification since colonization from the continent or other archipelagos has been greater, providing an element of palaeoendemism, which in turn contributes to the overall level of endemism.

In addition to the above, six out of the nine Azorean islands, i.e. Corvo, Flores, Terceira, Graciosa, Faial and São Miguel, have suffered from extensively explosive and frequent periods of volcanism (Strombolian and Plinian or Sub-Plinian type; França et al., 2005). The prevalence of more destructive types of volcanism can have dramatic effects on the biota of an island, and in such cases the maximum age of the island is likely to be, at best, an imperfect surrogate for the time available for diversification. The Azorean islands have been smaller in area and lower in elevation throughout their geological history compared to the rest of Macaronesia (Table 2). Due to this, such volcanic events are likely to have had a great impact on the Azorean biota, contributing towards its 'youthfulness' (Van Riel et al., 2005; Triantis et al., 2010). We thus agree with the early suggestion of Guppy (1917) that the Azorean islands are too young for the occurrence of extensive intra-archipelago radiations, providing part of the explanation for the Azorean diversity enigma.

\section{Geological formation: the intra- archipelagic missing step}

An additional, complementary explanation for the low endemism of the Azorean islands is provided by the 'intra-archipelagic missing stepping-stone hypothesis' (proposed by Triantis et al., 2010). Santa Maria was isolated for at least $4 \mathrm{Myr}$ after its formation, and before any other of the Azorean islands emerged. This long-term isolation has resulted in Santa Maria being not only the effective source for the colonization of other Azorean islands, but also the place of origin of a high proportion of current Azorean endemic lineages (Van Riel et al., 2005; 
Borges \& Hortal, 2009; Borges et al., 2010; Triantis et al., 2010; Schaefer et al., 2011).

As noted above, Santa Maria was the sole land mass of the archipelago for at least $4 \mathrm{Myr}$, and from around $4 \mathrm{Ma}$ to almost 0.05 Ma São Miguel was much smaller than it currently is. Thus, we argue that many lineages endemic to Santa Maria have either gone extinct during the $4 \mathrm{Myr}$ that this island was the only land mass present in the area andor have not been able to successfully colonize the rest of the islands until recently. Nevertheless, as Santa Maria was the first island to emerge, it is the island on which lineages have had the longest period of time to evolve. This is evident in: (1) the comparatively higher numbers of SIEs in Santa Maria for most taxa (Borges et al., 2010); (2) the genetic and morphological distinctiveness of this island's biota (e.g. Van Riel et al., 2005; Borges et al., 2007; Ferreira et al., 2011; Schaefer et al., 2011); and (3) the relatively recent origin of many of the diversification events currently underway within the central Azorean islands, compared to the older basal taxa from Santa Maria and São Miguel (e.g. Leptaxini snails, Van Riel et al., 2005; Trechus beetles, Borges et al., 2007; Tarphius beetles and Hipparchia butterflies, I. Amorim, unpublished data). Schaefer et al. (2011) provide further evidence in this respect, showing that Santa Maria lineages are, in general, genetically distinct from the rest of the islands (three of the four lineages that occur on Santa Maria exhibited ribotypes that were unique), and also that most diversification events are relatively recent, especially on the central Azorean islands.

\section{Archipelagic area in time}

Area has a profound effect on speciation rates; the probability of speciation occurring within a given region increases with its size (e.g. Rosenzweig, 1995; Losos \& Schluter, 2000). The total area of oceanic archipelagos is not static but changes as their constituent islands follow their developmental life cycle from youth, to maturity, to old age and eventual loss (e.g. Whittaker et al., 2008). The numerous seamounts that have arisen in the past and then foundered again add a further dimension of complexity to the evolutionary patterns of Macaronesia (Fernández-Palacios et al., 2011). Hence, in order to understand current patterns of endemism at the archipelagic level it is necessary to consider the variations in the total area of the archipelago through time. Although exact details are unclear, it is highly likely that the Azorean archipelago had the smallest total area during the last $10 \mathrm{Myr}$ and until recently (c. $1 \mathrm{Ma}$ ), compared to the Canary Islands and Madeira (which today has a third of the total area of the Azores) (see figs $1 \& 4$ in FernándezPalacios et al., 2011). This may have contributed to the lower levels of Azorean endemism compared with the Canaries and the currently smaller Madeira archipelago (see Table 2).

\section{THE LINNEAN SHORTFALL}

Schaefer et al. (2011) provide an additional explanation for the 'distinctiveness' of the Azorean endemic flora: the lack of a consistent and critical taxonomic framework for the floras of the Atlantic archipelagos, the so-called Linnean shortfall. It is true that despite the relatively thorough documentation of island biotas, new species are still being described even in the most studied archipelagos. This could, to a certain extent, have an effect on the observed biogeographical patterns. A simple comparison of the species lists published for the Canary Islands in 2001 and 2010 (Izquierdo et al., 2001; Arechavaleta et al., 2010) reveals that the known arthropods increased from 5668 taxa, 2172 of them being endemic to the Canaries (38.3\%), to 6138 and 2320 endemics $(37.8 \%)$. In the case of plants the figures increased from 1995 and 511 (25.6\%) archipelagic endemics to 2091 and $539(25.8 \%)$, respectively. Similar changes occurred for the Azorean archipelago, where between the 2005 and 2010 checklists (Borges et al., 2005, 2010) the numbers of known species changed from 2209 (267 endemics, $12.1 \%$ ) to 2298 (236 endemics, $10.3 \%)$ in the case of arthropods, and from 947 (68 endemics, $7.2 \%$ ) to 1110 (73 endemics, $6.6 \%$ ) in the case of vascular plants. Thus, we concur with Schaefer et al. (2011) that additional effort is required to increase our taxonomic knowledge of the Macaronesian island biota, especially for the poorly studied taxa. However, while there may be additional endemics to be described in the Azores, it is clear that the proportions of SIEs will remain well below those of the other archipelagos for plants, land snails and arthropods (see Table 2).

\section{CONCLUDING REMARKS}

Carine \& Schaefer (2010) proposed that a lack of past climate oscillations may have contributed to the low endemism in Azorean plants compared to the Canary Islands.
However, the bulk of the available palaeoclimatic data indicate that the climate of the Azores has been less stable than that of the Canaries. Moreover, the geological, geographical, genetic and ecological data (including those from Schaefer et al., 2011) support the proposition that the limited number of Azorean endemic species and their relatively broad distributional ranges (encompassing multiple islands), are better explained by other attributes of this archipelago. In short, the Azores are young, small and environmentally homogeneous compared to the other Macaronesian archipelagos. To untie the Azorean knot, a synthetic consideration of all these explanations is required; a single factor is not sufficient.

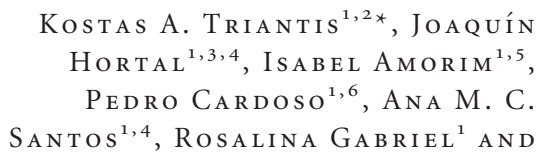
Paulo A. V. Borges ${ }^{1}$

${ }^{1}$ Azorean Biodiversity Group CITA-A, Universidade dos Açores, Pico da Urze, 9700-042 Angra do Heroísmo, Terceira, Açores, Portugal, ${ }^{2}$ Biodiversity Research Group, Oxford University Centre for the Environment, South Parks Road, Oxford OX1 3QY, UK, ${ }^{3}$ Departamento de Biodiversidad y Biología Evolutiva, Museo Nacional de Ciencias Naturales (CSIC), CJosé Gutiérrez Abascal 2, 28006 Madrid, Spain, ${ }^{4}$ Departamento de Ecologia, Instituto de Ciências Biológicas, Universidade

Federal de Goiás, 74001-970 Goiania, GO, Brazil, ${ }^{5}$ School of Biological Sciences, University of East Anglia, Norwich NR4 7TJ, UK, ${ }^{6}$ Smithsonian Institution, National Museum of Natural History, 10th of Constitution NW, MRC 105, Room E-509, Washington, DC 20560-0105, USA

*E-mail: konstantinos.triantis@ ouce.ox.ac.uk

\section{ACKNOWLEDGEMENTS}

We thank Mark Carine and Hanno Schaefer for helpful discussions about our manuscript, Jon Price, José Maria Fernández-Palacios, Luís Silva and Rob Whittaker for comments on previous drafts of this manuscript, and Hennig Adsersen and an anonymous referee for their insightful reviews. We are also grateful to António Frias Martins for making available to us the most updated data for Azorean land snails. K.A.T., P.C. and I.R.A. were supported by the Portuguese Fundação para a Ciência e a Tecnologia (FCT) grants SFRH/BPD/40688/2007, SFRH/BD/21496 
2005, SFRH/BPD/29578/2006 and SFRH BPD/44306/2008, respectively, J.H. by a Spanish Ministerio de Ciencia e Innovación Ramón y Cajal grant, and A.M.C.S. by a Brazilian Conselho Nacional de Desenvolvimento Científico e Tecnológico (CNPq) Junior Postdoctoral grant (510201/2010-5). This paper was also supported by the FCT projects PTDCBIA-BEC/100182/2008 for K.A.T. and P.A.V.B. and PTDCBIABEC/104571/2008 for I.R.A.

\section{REFERENCES}

Araújo, M.B., Nogués-Bravo, D., DinizFilho, J.A.F., Haywood, A.M., Valdes, P.J. \& Rahbek, C. (2008) Quaternary climate changes explain diversity among reptiles and amphibians. Ecography, 31, 8-15.

Arechavaleta, M., Rodríguez, S., Zurita, N. \& García, A. (eds) (2010) Lista de especies silvestres de Canarias. Hongos, plantas y animales terrestres. 2009. Gobierno de Canarias, Santa Cruz, Tenerife.

Avise, J.C. (2009) Phylogeography: retrospect and prospect. Journal of Biogeography, 36, 3-15.

Björck, S., Rittenour, T., Rosén, P., França, Z., Möller, P., Snowball, I., Wastegård, S., Bennike, O. \& Kromer, B. (2006) A Holocene lacustrine record in the central North Atlantic: proxies for volcanic activity, short-term NAO mode variability, and long-term precipitation changes. Quaternary Science Reviews, 25, 9-32.

Borges, P.A.V. \& Hortal, J. (2009) Time, area and isolation: factors driving the diversification of Azorean arthropods. Journal of Biogeography, 36, 178-191.

Borges, P.A.V., Cunha, R., Gabriel, R., Martins, A.F., Silva, L. \& Vieira, V. (2005) A list of the terrestrial fauna (Mollusca and Arthropoda) and flora (Bryophyta, Pteridophyta and Spermatophyta) from the Azores. Direcção Regional do Ambiente and Universidade dos Açores, Horta, Angra do Heroísmo and Ponta Delgada.

Borges, P.A.V., Oromí, P., Serrano, A.R.M., Amorim, I.R. \& Pereira, F. (2007) Biodiversity patterns of cavernicolous groundbeetles and their conservation status in the Azores, with the description of a new species: Trechus isabelae n. sp. (Coleoptera, Carabidae, Trechinae). Zootaxa, 1478, 21-31.

Borges, P.A.V., Abreu, C., Aguiar, A.M.F., Carvalho, P., Jardim, R., Melo, I., Oliveira, P., Sérgio, C., Serrano, A.R.M. \& Vieira, P. (eds) (2008) A list of the terrestrial fungi, flora and fauna of
Madeira and Selvagens archipelagos. Direcção Regional do Ambiente da Madeira and Universidade dos Açores, Funchal and Angra do Heroísmo.

Borges, P.A.V., Costa, A., Cunha, R., Gabriel, R., Gonçalves, V., Martins, A.F., Melo, I., Parente, M., Raposeiro, P., Rodrigues, P., Santos, R.S., Silva, L., Vieira, P. \& Vieira, V. (eds) (2010) A list of the terrestrial and marine biota from the Azores. Princípia, Cascais.

Braconnot, P., Otto-Bliesner, B., Harrison, S. et al. (2007) Results of PMIP2 coupled simulations of the Mid-Holocene and Last Glacial Maximum - Part 1: experiments and large-scale features. Climate of the Past, 3, 261-277.

Carine, M.A. \& Schaefer, H. (2010) The Azores diversity enigma: why are there so few Azorean endemic flowering plants and why are they so widespread? Journal of Biogeography, 37, 77-89.

Crowley, T.J. (1981) Temperature and circulation changes in the eastern North Atlantic during the last 150,000 years: evidence from the planktonic foraminiferal record. Marine Micropaleontology, 6, 97-129.

Emerson, B.C. \& Kolm, N. (2005) Species diversity can drive speciation. Nature, 434, 1015-1017.

Fernández-Palacios, J.M., de Nascimento, L., Otto, R., Delgado, J.D., García-delRey, E., Arévalo, J.R. \& Whittaker, R.J. (2011) A reconstruction of Palaeo-Macaronesia, with particular reference to the long-term biogeography of the Atlantic island laurel forests. Journal of Biogeography, 38, 226-246.

Ferreira, R.C., Piredda, R., Bagnoli, F., Bellarosa, R., Attimonelli, M., Fineschi, S., Schirone, B. \& Simeone, M.C. (2011) Phylogeography and conservation perspectives of an endangered Macaronesian endemic: Picconia azorica (Tutin) Knobl. (Oleaceae). European Journal of Forestry Research, 130, 181-195.

França, Z., Cruz, J.V., Nunes, J.C. \& Forjaz, V.H. (2005) Geologia dos Açores: uma perspectiva actual. Açoreana, 10, 11-140.

Guppy, H.B. (1917) Plants, seeds, and currents in the West Indies and Azores: the results of investigations carried out in those regions between 1906 and 1914. Williams and Norgate, London.

Hortal, J., Triantis, K.A., Meiri, S., Thébault, E. \& Sfenthourakis, S. (2009) Island species richness increases with habitat diversity. The American Naturalist, 173, E205-E217.

Izquierdo, I., Martín, J.L., Zurita, N. \& Arechavaleta, M. (eds) (2001) Lista de especies silvestres de Canarias (hongos, plantas y animales terrestres). Consejería de Política
Territorial y Medio Ambiente, Gobierno de Canarias, La Laguna, Tenerife.

Kim, J.H., Meggers, H., Rimbu, N., Lohmann, G., Freudenthal, T., Müller, P.J. \& Schneider, R.R. (2007) Impacts of the North Atlantic gyre circulation on Holocene climate off northwest Africa. Geology, 35, 387-390.

Knowles, L.L. (2009) Statistical phylogeography. Annual Review of Ecology, Evolution, and Systematics, 40, 593-612.

Losos, J.B. \& Schluter, D. (2000) Analysis of an evolutionary species-area relationship. Nature, 408, 847-850.

MacArthur, R.H. \& Wilson, E.O. (1967) The theory of island biogeography. Princeton University Press, Princeton, NJ.

Morey, A.E., Mix, A.C. \& Pisias, N.G. (2005) Planktonic foraminiferal assemblages preserved in surface sediments correspond to multiple environment variables. Quaternary Science Reviews, 24, 925-950.

Ortiz, J.E., Torres, T., Yanes, Y., Castillo, C., De la Nuez, J., Ibáñez, M. \& Alonso, M.R. (2006) Climatic cycles inferred from the aminostratigraphy and aminochronology of Quaternary dunes and palaeosols from the eastern islands of the Canary Archipelago. Journal of Quaternary Science, 21, 287-306.

Overpeck, J.T., Peterson, L.C., Kipp, N., Imbrie, J. \& Rind, D. (1989) Climate change in the circum-North Atlantic region during the last deglaciation. Nature, 338, 553-557.

Rogerson, M., Rohling, E.J., Weaver, P.P.E. \& Murray, J.W. (2004) The Azores Front since the Last Glacial Maximum. Earth and Planetary Science Letters, 222, 779 789.

Rosenzweig, M.L. (1995) Species diversity in space and time. Cambridge University Press, Cambridge.

Schaefer, H., Moura, M., Maciel, M.G.B., Silva, L., Rumsey, F.J. \& Carine, M. (2011) The Linnean shortfall in oceanic island biogeography: a case study in the Azores. Journal of Biogeography, 38, 1345 1355.

Serrano, A.R.M., Borges, P.A.V., Boieiro, M. \& Oromí, P. (eds) (2010) Terrestrial arthropods of Macaronesia - biodiversity, ecology and evolution. Sociedade Portuguesa de Entomologia, Lisbon.

Sjögren, E. (1973) Recent changes in the vascular flora and vegetation of the Azores Islands. Memórias da Sociedade Broteriana, 22, 1-451.

Stuessy, T.F., Jakubowsky, G., Gómez, R.S., Pfosser, M., Schlüter, P.M., Fer, T., Sun, B.-Y. \& Kato, H. (2006) Anagenetic evolution in island plants. Journal of Biogeography, 33, 1259-1265. 
Triantis, K.A., Borges, P.A.V., Hortal, J. \& Whittaker, R.J. (2010) The Macaronesian province: patterns of species richness and endemism of arthropods. Terrestrial arthropods of Macaronesia - biodiversity, ecology and evolution (ed. by A.R.M. Serrano, P.A.V. Borges, M. Boieiro and P. Oromí), pp. 49-71. Sociedade Portuguesa de Entomologia, Lisbon.

Van Riel, P., Jordaens, K., Van Houtte, N., Martins, A.M.F., Verhagen, R. \& Backeljau, T. (2005) Molecular systematics of the endemic Leptaxini (Gastropoda: Pulmonata) on the Azores islands. Molecular Phylogenetics and Evolution, 37, 132-143.

Whittaker, R.J. \& Fernández-Palacios, J.M. (2007) Island biogeography: ecology, evolution, and conservation, 2nd edn. Oxford University Press, Oxford.

Whittaker, R.J., Triantis, K.A. \& Ladle, R.J. (2008) A general dynamic theory of oceanic island biogeography. Journal of Biogeography, 35, 977-994.

Editor: José Maria Fernández-Palacios

doi:10.1111/j.1365-2699.2011.02623.x

\section{Putting biogeography's cart back behind taxonomy's horse: a response to Triantis et al.}

\section{ABSTRACT}

In a recent paper, two of us discussed diversity patterns and diversification processes in the Azores flora. Triantis et al. (2012, Journal of Biogeography, 39, 1179-1184) challenged our hypothesis that palaeoclimatic differences had an effect on diversification rates and suggested that area, island age and isolation explain diversity patterns. They did not, however, fully address the results from our subsequent paper, in which we showed that diversity patterns evident from phylogeographic studies differ markedly from those suggested by checklists. Checklists are working hypotheses and we suggest that the discrepancies evident between molecular data and checklists may be indicative of deficiencies in our taxonomic understanding of the Azores flora. Patterns of molecular and morphological diversity need to be better understood, and the discrepancies between checklists and molecular data accounted for, before we can establish the relative importance of factors such as palaeoclimate, area, island age or isolation in generating endemic diversity patterns in the Azores flora.

Keywords Azores, Canary Islands, diversity enigma, Linnean shortfall, Macaronesia, palaeoclimate.

In a letter to Joseph Hooker dated Christmas Day, 1844, Charles Darwin (Darwin Correspondence Project, 2012, letter 803, p. 3) commented on a recently published enumeration of the Azores flora (Watson, 1843) and noted: 'Watson's Paper on [the] Azores has surprised me much; do you not think it odd, the fewness of peculiar species...?'

More than 160 years later, the patterns of Azorean plant diversity that (briefly) puzzled Darwin remain to be fully explained. Our two recent papers (Carine \& Schaefer, 2010, hereafter C\&S; and Schaefer et al., 2011a, hereafter SEA), sought to document and explain those patterns. Understanding the evolution of the distinctive but poorly studied Azores flora has the potential to inform our appreciation of the processes generating island plant diversity patterns more generally and we therefore welcome the interest in the topic that our papers have stimulated, notably the correspondence article by Triantis et al. (2012, hereafter TEA). The reply of TEA does, however, contain misconceptions and omissions relating to the findings of C\&S and fails to take into account fully the results and conclusions of SEA. Here, we address these issues and highlight what we believe to be the key challenge to understanding patterns of diversity in the endemic flora of the Azores.

\section{THE PATTERN}

C\&S described patterns of diversity in the Azores flora based on the taxonomic concepts used at that time and that are still reflected in the currently available checklist data for the Azores (Borges et al., 2010). Analysing those data, C\&S showed that the Azores is unusual not only in the apparently low number of endemic species (as pointed out by Darwin) but also more specifically in the low number of single-island endemic taxa (SIEs) and the resulting left-skewed PKI curve (presence in $k$-island, i.e. the distribution of endemic taxa per number of islands of occupancy). Thus, in the Azores, endemic taxa that are apparently distributed across the entire archipelago constitute a much larger proportion of the endemic flora than do single-island endemics. In contrast, in the eight other oceanic archipelagos investigated by C\&S [Canary Islands, Madeira, Cape Verdes, Hawaii, Galápagos, Marquesas, Society Islands, Ogasawara (Bonin) Islands], single-island endemics account for a substantially greater proportion of the endemic flora than do endemics that are widespread across the archipelago.

In addition, $\mathrm{C} \& \mathrm{~S}$ used distribution data in conjunction with ecological data to identify genera within which either interisland allopatry or ecological speciation may have occurred. Contrary to the suggestion of TEA, this analysis was performed on the complete endemic angiosperm flora with the nine lineages identified (Table 1 in C\&S) constituting all lineages that contained two or more endemic taxa. C\&S found instances of putative allopatric diversification to be even more limited than putative instances of ecological diversification. As C\&S (p. 82) noted: 'The limited incidence of adaptive, ecological speciation in the Azores... is consistent with the limited ecological diversity of the islands. However, the limited incidence of inter-island allopatry... is surprising when inter-island distances in the archipelago are considered'. This was the pattern that they sought to explain.

SEA subsequently collected populationlevel genetic data from a range of Azorean endemic plant lineages to further test the patterns observed. In marked contrast to the pattern suggested by checklist data, molecular data indicated that allopatric diversification has been common in the archipelago's endemic flora. Molecular diversity in most lineages examined showed a geographic signal and the data suggest that, at least at the molecular level, SIEs are more common than previously documented, with even young islands having endemic entities. SEA sampled c. $11 \%$ of the endemic flora. We have since continued to sample additional endemic vascular plant lineages and have found further instances of previously overlooked diversity in Smilax, Ranunculus and Centaurium (H. Schaefer, unpublished data), and also in Viburnum and Leontodon (M. Moura et al., unpublished data) but so far not in Bellis or Rumex (H. Schaefer, unpublished data). Overall, with nearly $20 \%$ of Azorean endemic lineages now sampled from two or more islands, the patterns documented by SEA are still evident and still differ markedly from those suggested by checklist data. We are continuing to expand this dataset. 